\title{
ON THE NEED \\ OF RECONSTRUCTION OF THE RESEARCH AREA IN THE INTERNATIONAL RELATIONS. Reflections of the political-normative, systemic and metaphorical nature
}

\author{
by Teresa Łoś-Nowak
}

At the turn of the $21^{\text {st }}$ century, under the influence of "quick transformation" undergone by the international relations, we have rather to do with "a carnival" of theoretical approaches competing with each other. Undoubtedly, it hampers the discourse about the research area within the scope of what is usually defined as international relations, and about epistemological condition of the discipline with over 100 years of tradition. In this theoretical chaos there are being posed questions if the international relations are "clearly defined domain of intellectual reflection, if they have specific features distinguishing" them against other social sciences, or if it is possible to create universal mega-theory in the international, dynamic, diverse and energetic environment, and if yes, then further questions are appearing. They concern two issues: ontological beings around which the international relations, seen as "autonomous," scientifically clear discipline, would consolidate, and methods of acquiring knowledge about it. Those who doubt, especially philosophers and sociologists, pose also questions if and how much it is possible to get objective knowledge, that is not burdened with the reflex of subjective system of values, ideas and experiences of a researcher.

This kind of questions has been known since publishing by M. Wight in year 1966 famous article - manifesto with symptomatic title Why is 
There No International Theory? The problem was sharpened by a discussion about the model of science and understanding the scientificity that took place since the half of nineteen sixties. The breaking moment was publishing in year 1962 Thomas Kuhn's dissertation titled Structure of scientific revolutions and numerous works about the theory of international relations. As examples we may mention such fundamental works as Contending Theories of International Relations. A Comprehensive Survey by J.E. Dougherty and R.L. Pfalzgraff Jr., World Society by J. Burton, Theories of International Relations - group work edited by exquisite researchers of the international relations (S. Burchill and A. Linklater), War and Change in World Politics by R. Gilpin, Controversies in IRs Theory by C.W. Kegley, R. Keohane, J. Nye, R. Krasner, J. Rosenau and many others.

\section{WOULD IT BE POSSIBLE TODAY FOR M. WIGHT TO WRITE HIS PROVOCATIVE ARTICLE CROSSING OUT THE OPPORTUNITY OF BUILDING THE THEORY IN INTERNATIONAL RELATIONS AND WHY?}

When trying to answer equally provocative questions, one shall first of all pay attention to the depth and scale of qualitative and quantitative changes that have occurred in the international system and environment since the moment when $\mathrm{M}$. Wight wrote his provocative text, as well as to how those changes have influenced perception of the world and mechanisms controlling international space, which is "incorporeal" for Wight. This procedure forces a researcher to need a redefinition of this space and redefinition of participants of the international relations, as well as to reach for methods in classical international relations that are unnoticed or underestimated. It also allows to look at the international relations as a discipline fulfilling methodological standards of academic discipline dynamic, searching and open for examined reality, expressing by this the need of getting it to know, understanding and improving. It is also worth to think about how much those provocative theses about the impossibility of building a theory of international relations "spread" in the light of deep changes in the international environment, its subjective and objective 
dimension, transformations undergone by states - still main players of international relations, their main attributes, hierarchy of needs and interests. This reflection should also concern the interdisciplinary character of international relations and applied language.

Taking into consideration changes that occurred in the international environment, its subjective and objective dimension, one can assume that M. Wight theses from the nineteen sixties about the impossibility of constructing the theory of international relations due to methodological weaknesses of the discipline, numerous borrowings from experimental sciences or "the lack of appropriate language in which one can theorise about global politics" do not stand confrontation with reality. It concerns especially fundamental for M. Wight thesis about the impossibility of breaking the dichotomy of "internationality" and "internality" of both environments, their specificity, type of management, attributiveness of a state as an internal sovereign, separateness of aims chosen by states and non-territorial "players," present in "incorporeal" space of world politics ruled by laws, regulations, norms, values different from the environment inside a state. We may recall here great achievements of the international relations. One may also recall the thesis of well-known Polish scientist in the area of international relations, author of the first work popular in its assumptions - R. Bierzanek, who is expressly distancing himself from the charge of the lack of scientificity of the discipline due to the lack of unambiguously clear research area, its own "area of activity," field that no one can access. R. Bierzanek wrote that in science there were no areas "reserved" for particular disciplines that could not be accessed by other researchers, humility in relation to science did not allow for such an ignorance. The attitude of rejection, appropriation of research "fields" makes science only poorer, leads to its "finding itself in the backwaters." This in turn does not serve world's development, does not show directions of its development, ways of solving old and new problems, with which people are confronted and which we are not always able to solve acting in "separation" from other disciplines.

The world described by M. Wight and other representatives of the rationalist approach connected with such classics as $\mathrm{H}$. Grotiusz and E. de Vattel has changed radically, both if it is about the way of functioning of 
a state in the anarchist international environment, functions traditionally performed by a state, meaning of state borders, integration forms, etc. This change, "written into" the history of international relations, states, their organisational forms, wars or international systems, forces the need of new look at the reality around us and reaching for new cognitive methods and techniques. Otherwise, this charge of being static, moral relativism and low susceptibility to changes in the international relations strengthened by neoliberal and post-positivist literature will be justified. That change would surely have been noticed by $M$. Wight if he had been writing his manifesto and intellectual provocation at the same time today.

What is changing in the postmodernism is first of all thinking about the world, its complicated nature, states and other participants of international relations, multitude and pluralism forcing new forms of connections and bonds designated by this pluralism and globalisation. This in turn generates problems which modern states, still the most important participants of international relations, are not capable of solving without cooperation with international organisations, corporations and crossborder structures. These facts seem to bury the "autonomy" of internal and external environment that was correct in the past, but today is rather symbolical. It was that obvious fact what revolutionised internal and external politics of a state, particularly intensified its mechanism of adaptation to the international environment, solutions dominating in it, strategies, etc. Also the concept of social order has changed. Although we are still far from the ideal of international society, it can not be excluded that its value increases in the post-bipolar era. It can be noticed for example in the need of legitimisation by the majority of modern states creating international society of such ideals as human rights, rules of democratic governance or preferences for solutions without using power, dialog taking into regard cultural and religious differences. Actors of modern conflicts constitute the factor that has radically changed. More and more rarely we are confronted with conflicts between states. There dominate conflicts inside countries with results crossing over state borders, for example in the form of intensified migrations. Understanding of the modern times together with their changing nature requires a change of self-awareness of people of the era that wants to define its diversity by distancing itself 
from the modernist or pre-modernist age. That is because the reality "appears here as very flexible and able to be created in the course of performed interpretation (performed individually by an intellectualist) or together by subjects »submerged « in this reality." In my opinion, with such a changed reality of the postmodern world one can make an attempt of new look at theses of M. Wight concerning the weakness or explanatory nothingness of the international relations.

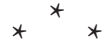

These changes, evident for an objective observer, require new considerations about intellectual condition of the international relations, their explanatory potential, and sometimes revision of simplified theses about its intellectual "shallowness," just as frequently observed, but harmful for science attitudes depreciating achievements of various, sometimes opposing theories, schools and approaches. I do not want to say by this that discussion between various schools and their representatives is needed. However, it should not close itself in the attempt of proving its truth and superiority, but in mutual inspiration breaking through the weaknesses of analytical-empirical and heuristic-historical model of science in the world of ideas, values, interests.

While not solving here the historical dispute about "what the science is" and what decides on its "scientificity," it is worth to emphasise that it symbolises the effort of human beings aimed at "getting information allowing for understanding their environment and themselves." It can be acquired with "common sense" or by preferring scientific approach. The latter differs from the "common sense" one by meaning "specific, socially created and accepted set of principles, norms, rules, to which epistemic behaviour shall be subordinated, leading to acquiring information allowing us to know and understand." When understood in such a way, it expresses the need of constructing model solutions verified empirically, for example the conception of subjectivity and participation in international relations. In the international environment characterised with great level of diversity of phenomena within the framework of the same set of subjects (e.g. states) it allows for finding "alternative, incomplete conceptions, replicated in the real world." 
Followers of such an understanding of science and scientificity see in it a chance for constructing models of changes in the field of international relations, for identifying carriers of these changes and their cognitive value. This attitude may facilitate the process of cognition, understanding, explanation and prognosis. It allows also for analysing these changes and comparing with those escaping simple "matrix" of e.g. realism, yet today too static and less progressive, post-behavioural construction of international system and systemically determined relations. On the opposite side of scientificity there is different model. Its symbol is rich, internally diverse post-positivist presentation proposing highly intersubjective interpretation of international relations with a certainty that imitating natural sciences does not have any sense "when it comes to human and social matters." So the fact that theory in the international relations is still developing should not be perceived as a proof of its weakness. Maybe taking into regard multidimensional structure of modern knowledge one should consider what is an indication of annulling divisions between disciplines in the process of reconstructing research area in the international relations, especially in the sphere of theoretical inquiries "where theory is perceived more and more often as common heritage and cumulated foundation of social sciences." Scientific knowledge is subject to process of reorganisation and restructuring due to the pressure of two opposite tendencies: dividing and unifying.

General plea entered to researchers identified with the positivist methodology is the disability of showing ways of progress, strengthening found social inequalities, domination of states in the group of participants of international relations, especially strong ones over weak ones, as well as "disability of transformations in the international system" natural in such a perception of international relations. Emancipating role of knowledge, concentration on its ethical-moral message and functions is supposed to - according to representatives of the post-positivist school, especially critical theorists and constructivists - identify more efficiently new causative factors and powers of changes in the international system and world politics.

Inasmuch as for representatives of the realistic school in the international relations the formation of a state with its territoriality and sover- 
eignty meant "milestone progress" in the international relations history, in the late Westphalian system "progress" seems to be not the "disappearance" or decline of traditionally understood state, but its radical reorientation for international environment and changes occurring in it. This in turn constitutes revolutionary change of basic problems on which modern international relations should concentrate, and the fact of extending traditionally formulated limits of intellectual discourse in this area should not mean distancing from scientific knowledge brought by its precursors into its circle. Noticeable particularly in the past 20 years strong inclination on the image of international relations science of the intellectual achievements of philosophy of politics, social theory, sociology, culture studies, psychology, causes that discussion about scientific status of internationality has been reanimated again. Significant role in this process is played by exclusion from the discourse of the problem of interdisciplinarity in general, including in the international relations. One may even risk a statement that it is the attitude being another attempt of discrediting achievements of the international relations, treated by its so called "outsiders" as "a part of a structure of intellectual oppression." This circumstance is in a reasonable way perceived as questioning, sometimes excluding, "classical" achievements of the international relations and settling them on self-reflective, occurring in constructed in researcher's mind presentation of the world, powers and procedures existing in it and recognised or underestimated by researchers of the realistic trend, on circling own understanding of the postmodern world and its problems.

However, on the other hand, criticism and even objection to all that can take a form of model projections of subjectivity (e.g. state), its attributiveness (e.g. sovereignty), hegemony (as a type of order), anarchy (as a permanent feature of international environment) with regard to its arbitrariness, it locates post-positivism in the circle of postmodern thought where strong institutions, international orders, political values and labels ascribed to them become "discursive phenomenon." Their sense becomes relative against attitudes that ascribe into postmodern discourse of individualised world, in an unordered sense, in doubting the cognition as an objective process. Postmodern mentality resigns from axioms for which modern thought was fighting so much, satiated with enlightening ideals, questions 
lasting foundations on which one was building the order, there were coming into being national states and one determined principles that should be obeyed in mutual relations, putting an accent on uniformity and homogeneity of communities. Such an example is postmodernism, "one of the most influential and controversial theoretical approaches" in researches of international relations, at the same time trying to break through in an interesting form this dichotomy of "internationality" and "internality," imperfection of the language of internationality, relating in an innovative way to such notions as "politics", "state", "sovereignty", "territoriality", "anarchy", "strength/power", "war," hence key notions for the "inside" of a state and its external environment. Postmodernism proposes deconstruction as an instrument, understood as "the way of radical violation of what we take as strengthened concepts and conceptual way of treating them."

This attitude in my deep certainty ascribes into the trend of discourse about the need of reconceptualising research area in the international relations, where division into "internationality" and "internality" is illusory or problematic. It means the gauntlet thrown down to thinking in the M. Wight style and its fundamental thesis about the impossibility of building a theory of international relations due to significant qualitative differences between international and intrastate environment.

\section{WIGHT AND THE POSTMODERN WORLD}

In comparison with "modern" model of international relations defined metaphorically as "Westphalian," settled on existence and activities of national state, with a sovereign and circled borders, "postmodern" or "late Westphalian" world differs from its original. Firstly, Westphalian model is appropriate for decidedly state-centric world, closed "from inside" with an authority having the exclusiveness for controlling social life and realisation of 4 basic values, that is safety, order, justice and welfare. Secondly, clear distinction between an internal sphere of a state and international sphere of a political life. Thirdly, coming into existence of a new type of relations rather "between equals" (sovereigns) than "above sovereigns," together with the development of international law. 
On the other hand, post-Westphalian or late Westphalian world, to recall definition of M. Pietraś, is the world which designation is heterogeneity of subjects, including huge number of state borders having the ability of cross-border behaviour, that is performed "across." Late Westphalian world is also the world where the process of "reconfiguration of anarchy of the international environment" occurs, where international relations concentrating its existence on relations "between" states enter the phase of "post-interstate international relations." State-centric world gives way to "multicentric world," where binarity of relations, behaviours and rules loses with pluralistic relations. In this world it is more and more difficult to separate what constitutes internal matters of a state and what belongs to the internationality sphere, that is international matters. Even "territorial imperative" fundamental for a state does not have nowadays such a great meaning as in recent past. More and more depends on supranational structures coexisting with sovereign authority of territorial subjects. In "global village" also the field of manoeuvre "shrinks" in foreign and security politics - areas that are symbols of sovereign power. In respect of the above-mentioned, there is a question if rationalism included in the way of thinking of $\mathrm{M}$. Wight about international relations stands the test of time in "the world spinning around" and which theses of "manifesto" of this classic of the international society were verified by reality.

Distinguishing characteristics of "international" and "intrastate" environment constituted for Wight an important obstacle rendering impossible the construction of an explanatory theory in international relations. This, in turn, due to existence of such a fundamental limitation, could have been at the most the history of international relations, international politics, diplomacy. Borrowings of notions appropriate for a theory of politics and political philosophy could not have explained anything due to Wight, because they were not giving instruments allowing for "managing" phenomena occurring in open, incorporeal international space. That "incorporeality" of the international space, where sovereign states function was making a trouble in explaining the phenomenon of relations among sovereign states by notions borrowed from other scientific disciplines for explaining relations in the state - an individual, state power - individual system and application of such notions relevant to political science as 
authority, compulsion in order to determine these relations. According to Wight, power always includes presumption of relations based on superiority and domination. In turn such a character of relations in contacts between sovereigns is unacceptable. Thus, application of notions adequate to research the phenomenon of politics is not a good instrument allowing for explaining relations in the international environment, in which sovereign subjects function.

Really each one? Does really language of the political science is so inadequate to describe and explain processes occurring in the sphere of "external" activity of states and new subjects functioning in the international environment, new rules, norms, institutions significant for the international system? If yes, than there arises a question about the offer so precise and at the same time rich, that it could reasonably pose questions and give reasonable answers to them. I am convinced that knowledge about international politics, history of international relations, history of diplomacy and explanatory weaknesses of arising discipline perceived by M. Wight are shared by modern researchers. It does not shatter the fact that the international relations develop themselves enriching knowledge about the world, its complicated construction, states and challenges with which they are confronted, threats, new institutional solutions, etc. Modern researchers still use language of politics, but it is significantly enriched with new perception of phenomena and processes present in social and political life for "ever-more" and new ones, characterising another developmental phase of the international relations, keeping the awareness that a theory of international relations is/should be concreting theory of politics, taking into regard the specificity of the field of international and social relations. Such a controversial definition, according to Wight, taken from the science of politics, like "power" has been enriched with absent or strange contents and still serves as a good instrument of description and explanation. Also the language of international relations has been enriched - it defines phenomena and processes which dominated modern world of international politics, and which explanation requires new language, notions and designates. Description of relations occurring in "empty" international space lacking superiority and subordination becomes real "when a researcher makes up his/her mind concerning choices of notional 
apparatus with which researched object is going to be described". Moreover, language with which one passes on knowledge about international relations is a rich material reflecting the specificity of time and space being the subject of research, systems of signs and notions relevant to them.

Rationalism included in the way of thinking of M. Wight about international relations indicated the anarchy of international environment, however it did not treat it as a feature rendering impossible realisation of external politics by a state with its full consequence for internal politics. The most often plea entered by M. Wight (and other representatives of the international relations school) against followers of political realism concerned its tendency to perceive a state as an actor preferring selfish behaviours and attitudes against the others, disability of pro-social attitudes and progressive behaviours towards others, often the weaker ones. However, such an assessment of a content of realistic paradigm devaluates itself and leads to intellectual backwaters, when we become aware that it is not possible to provide own nation with "good life" in isolation from others, and "survival" is modernly possible in cooperation, that realism does not treat the anarchy of international environment as a place after which confrontation dominates over cooperation, that prudence and rationality are a premise of its successes in foreign politics. Even the category of "power," the most controversial and questioned by Wight as useless explanatory device in the theory of international relations, because borrowed from the language of the theory of politics, in its ontological layer enriched the conceptual scope of key value according to Wight, that is physical "survival" in anarchic world of territorially closed political community with such components as international norms and institutions that together with extension of a field of cooperation in open international space can significantly extend "well-being" in the sphere of internal existence. They fill this incorporeal space with "internationality."

In modern, pluralist political communities created by states and nonterritorial communities, also other notions applied in the political science, such as for example "democracy," "justice," "effectiveness" present from the beginning in a language of the theory of politics and moved to relations between participants of international relations, fill an "international" space and build new type of relations in contacts with sovereign participants. It 
bases on methods and means of actions known from the history of international relations, but also builds the model of behaviours, which strength/ might/power has a very diverse content. It should constitute also ontological layer requiring new explanatory models. It will allow for more precise presentation of a nonsense of dichotomous and today artificial division into "internal" and "international" spheres as appropriate for state politics towards obvious today phenomena of implosion and resulting from it processes of penetration of problems from "inside of a state" to "international environment" and opposite way, disappearance of former functions of borders, weakening of old institutions and structures of controlling the international environment, as well as replacing them with institutions and structures with qualitatively new features. So the challenge for theorists of the international relations of the postmodern age would be the reflection about the phenomenon of implosion, that is "forcing into" and mutually penetrating spheres of "internal" activity of a state and its "external" behaviours, attitudes, strategies, politics. Particularly important issue would be the examination of what are consequences for a state and other participants of international relations, international environment, rules valid in it, value and quality of relations in its structure of relations of its external and internal function, as well as for efficiency of its application in relations with subjects with various potentials and the process of moving it from the authority of a territorial sovereign to the other important subjects of international relations.

Dichotomous division of M. Wight into the "internationality" and "internality" spheres as separate beings is explained by Alan C. Lamborn, indicating premises hampering communication of researchers representing many options, paradigms, historical traditions. In the essay titled Theory and the Politics in World Politics he notices not without right that "many competing intellectual traditions and competing research programs in the international relations share fundamental set of meta-theoretical assumptions about processes of strategic interactions in politics," what, as he suggests, may and should constitute the area integrating their research instruments, language and methods. However, on the other side between us there are differences that seem so significant that render impossible this process. The underdeep of them are various "different empirical assump- 
tions" concerning actors and their specificity, types and kinds of problems with which they are confronted, models of behaviours in the international environment, areas, so their ontological field. In this state of matters, A.C. Lamborn proposes the performance of "regular identification of shared assumptions." This simple procedure would allow for elimination of many false problems from the discipline. This in turn - as Lamborn optimistically noticed - "would create heuristic instrument for research that can connect international and internal politics, as well as lead researchers to create more general theory of the international relations." The best way of overcoming these obstacles would be "a return to basic principles explaining the way the politics functions."

It is indeed interesting perception of a discourse about the theory of international relations, especially its course in past 20 years. However, is it able to break through a resistance of a matter, that rests on attitudes of representatives of various schools, trends and research directions in the international relations? It is hard to judge, but worth to discuss. The paradox of this discourse relies on that when dominated by philosophers, sociologists, anthropologists, culture scientists and psychologists, it introduces to the international relations elements relevant to disciplines "performed" by them and tries to give it tone and depth reflecting their research fascinations, define aims and ways of research, as well as methodology. However, it is worth to stop there and start material debate. Maybe it would help with building new bridge between "internationality," domain of "survival" of international relation participants, and "internality," which domain is well-being. As experiences of strong and well-prospering states show, this is not achievable by exposing limits of internality, closing to inside. The age of "global globalisation" provokes even research teams to formulate very bold theses about "the possibility of arising qualitatively new global political community, and even something in a type of global state." However, it would not mean disappearance of a state as an idea, market state, formed symbol. 


\section{RESET OR RECONSTRUCTION OF THE RESEARCH AREA?}

It seems that discussion occurring in the area of international relations concerns the research area, in which there continues "never-ending spectacle" of world politics, coming into being and fall of new kingdoms, new actors and rules in new, not so "incorporeal" space of international relations, new institutional solutions, searches for new forms of governance in multicentric environment, but also problems with timeless dimension of timeless value.

Traditionally, research area in the international relations involves states and non-territorial subjects of international relations and issues connected with their functioning, so this is the international environment, its specificity, structure and organisational forms of international space, international order and stabilisers of its balance and destabilisers of changes that they bring, problems of peace and safety. In the phase of "late Westphalian" international relations changes concern mainly a state and symbols expressing its essence. Changes involve also the system of international relations and international environment. Also the character and mechanism of mutual affection on each other by participants of international relations are changing. These changes obviously provoke to questions about their essence, depth and meaning for the international order, horizon of international space is getting longer. The world of the $21^{\text {st }}$ century creates the area intriguing for scientific reflection. Maybe its deconstruction and repeated reconstruction is a move in the right direction. One cannot also exclude the strategy of reset. If reconstruction, then still important are questions and directions, if reset of research area, then is it important what is going to be in it?

Assuming that proposition of "reset" seems to be an intellectual provocation, when it comes to identification of a research area in the international relations of the late Westphalian world, it is more reasonable to stop on projection of a reconstruction of political, institutional, normative and functional research area, which occurred and still occurs in post-bipolar world, where "old," characteristic for Westphalian order rules, actors, principles, norms and institutions coexist with qualitatively "new" changes in the international environment. 
First direction is leaving the dichotomy of "internationality" and "internality" for the benefit of synergy of both spaces and research of consequences of imploding external world to the inside of states. It generates natural process of spatial extension of international relations, multiplications of decision-makers participating in mechanisms of controlling the international environment, phenomenon of "reconfiguration" of its anarchy. Under the influence of globalisation territoriality takes new dimension, material field of international relations changes, more and more often two spaces are "descending" on each other: inside and outside of a state, international.

Mutual penetration of intrastate problems with the international relations space and transferring the latter ones inside a state, course of transferring decision-making processes made in closed space of a state to essentially open essence of international environment's space causes that thesis about a dichotomy of spheres defined as "international" and "internal" and relevantly international theory as "a theory of survival" and the theory of politics as "a theory of well-being" seems to be an anachronism.

Reconstruction of a space of international relations involves rich and diverse group of participants of international relations. Territorially and nationally organised actors have been existing scarcely for 300 years. In the history of mankind it is "historical moment" - so important that one observes with the inquisitiveness of a researcher the deepest metamorphosis that it has been undergoing in recent years. Although it still exists and not much seems to indicate "the end of Leviathan," nevertheless the way of organising, rules of functioning, relations with the environment, performed functions and expectations related with its existence are changing. It may symbolise that there comes a state different than the one we know, about which Z. Bauman writes in his dissertation Wasted Lives in year 2004.

It becomes obvious that old organisational forms of political-territorial area limit chances of states for "good life" allowing scarcely for "survival." However, it exists. In order to fulfil requirements of its own community, but also of an international community, "lasting" means regress, stepping back, weakening. Due to that, a state understanding well its historical 
mission and obligations towards its own nation has to step forward towards solutions, to which it is not used. It has to find for itself a place in new geopolitical, geoeconomic, geocultural area and build its future in it. Certainly modern state "is not almighty inside and outside." Globalisation - repeating after A. Giddens - synonym of late modernity transforms mostly actually a national state, symbol of Westphalian world. But also globalisation does not liquidate a state. Oppositely, it only forces on it the necessity of revising its classical identity, its internal functions, what in effect leads to the evolution of state structures, to their opening for the world and environment at a greater degree than anytime in the past. However, states in this process do not lose their sovereignty, and what is the most important, symbols of global processes - big corporations, but also existing regional organisations with global or supranational scope would not exist against or over a state. The metaphor of "global governance" and institutions hiding behind it do not have at their disposal the monopoly for using violence towards sovereign state, nor they can function with its omission. Nevertheless, there is no denying that those are right who emphasise the fact that modern state has signs of performative being, created by specific practices, actions, decisions. Accordingly in postmodern perception it is in continuous process of "coming into being," "...in continuous process of concretisation." R. Ashley - leading representative of the postmodern trend - suggests for example that subject aspiring to the status of state has to "be up to a task" in action, manifest the ability to govern a state (good governance). So it may exist performatively or else as a model subjective structure. Model subjective structure seems to be here a rhetorical phrase, because for Ashley matter only subjects that are up to a task in the art of governance, i.e. the basic factor constituting them. The others are only substitutes unable to compete with other, better organised non-territorial players. Weakening position of many of them poses in respect of it a series of questions about the sense of their lasting, suggesting their fleeting attractiveness or - what seems more significant from the postmodern perspective - the purposefulness of repeated thinking through factors constituting a state, repeated reaching for sources of a modern state. It is smart and interesting construction of state. However, it does not determine by what the process of "becoming 
a state" differs in the perspective of postmodernists from the model of explaining this phenomenon by K. Holstie or J. Rosenau. The art of performance is slowly being learned by the European Union with the communitiveness in the economic sphere, common foreign and safety politics, and this is what fills the ontological space of international environment. However, it is not a state and it seems that "the state of Europe" will stay in the sphere of ideas and symbols.

It is worth to enrich incorporeal space in modern world, mentioned by M. Wight, first of all with a research of a nature of the social world and what constitutes it, so ideas, values, experience of a researcher, knowledge treated as a key to cognition and exploration of this timeless phenomenon which is a state, even if one repeats after postmodernists that it is the subjective creation of people, different due to imaginations about it. Important and cognitively interesting may be a research of the idea of a postmodern state, because for a researcher from the constructivist trend it exists as its intersubjective awareness. International relations are a creation of ideas, values, experiences, so it is them what should be placed in the research field of the international relations and showed how they see a state and its functions in the age of "uncertainty." Response saying that constructivist or deconstructivist construction of the phenomenon of a country and state, as well as "narration about it," may lead to scientific nihilism and may be perceived as a sign of specific arrogance and negation of forms and means of scientific cognition different from the classical one, a sign of the lack of epistemic attitudes. They in turn order a humility towards other versions, other narrations, other ways of perceiving the reality. In such a breakdown of attitudes, assessments and opinions it is hard to get good diagnosis about the future of the state, its role and position in the post-industrial society, international system, forms of institutionalisation of international relations, their effectiveness, etc.

Second direction is the enrichment of language to describe new phenomena, processes, actors and rules that will be obeyed in postmodern international space. This process has already been developing. Thesis about the lack of language suitable for reflection of a phenomenon such as international relations in the post-Westphalian order, lacks its attractiveness due to significantly enriched language of description and explanation 
of new ideas, phenomena and processes occurring in the international area, so far perceived only in the convention of the world of national territories, politically ordered globe, with governments hiding behind the idea and legal norm of sovereignty. Being the symbol of novelty, they force the need of description and explanation, but also interpretation of changes that they symbolise. It concerns also researchers, for whom international area and environment has metaphysical value. Still real value of such categories as territory, institutions, power, but also new rules, normative practices, values allowing for understanding modern, real world, increases under the influence of advanced processes of globalisation. 